\title{
Efecto del Láser Infrarrojo sobre Células Tiroideas
}

\author{
Infrared Laser Effect on Thyroid Cells
}

\author{
Ricardo Cornejo*; Roberto Jaramillo**; Orlando Garrido** \& Luis Vergara*
}

CORNEJO, R.; JARAMILLO, R.; GARRIDO, O. \& VERGARA, L. Efecto de láser infrarrojo sobre células tiroideas. Int. J. Morphol., 34(2):498-502, 2016.

RESUMEN: Diez ratas Sprague Dawley de 4 meses de vida y peso aproximado de $250 \mathrm{~g}$ fueron divididas en dos grupos de 5 animales cada uno, el grupo A se mantuvo como control y los animales del grupo B recibieron estimulaciones con láser infrarrojo en la tiroides con dosis de $16 \mathrm{~J} / \mathrm{cm}^{2}$ durante 15 días consecutivos. Posteriormente las ratas fueron sacrificadas, se extrajeron las respectivas tiroides siendo procesadas para microscopía óptica y se obtuvieron placas histológicas y micrografías de tiroides con aumentos finales de hasta 1000X, las cuales fueron sometidas a estudios morfométricos para determinar en 100 células foliculares: número, áreas y perímetro tanto celular como nuclear, además de disposición coloidal y presencia de vasos sanguíneos. El análisis de los resultados entre las 100 células foliculares pertenecientes a tiroides normal y estimulada revela que existen marcadas diferencias en todos los componentes analizados los que se podría traducir en distintas funcionalidades en el metabolismo de las respectivas glándulas.

PALABRAS CLAVE: Células tiroides; Células foliculares; Morfometría; Láser infrarrojo.

\section{INTRODUCCIÓN}

La tiroides es una glándula endocrina localizada en la parte anterior y a ambos lados de la tráquea en la base del cuello a nivel de las vertebras C5-T1 y su tamaño es muy variable ya que suele pesar entre $15-20 \mathrm{~g}$ en el adulto. Posee una capsula delgada de tejido conjuntivo denso irregular y colagenoso donde los tabiques de la cápsula subdividen a la glándula en lóbulos izquierdo y derecho, que están conectados a través de una delgada lámina, el istmo (Silverthom, 2007).

La glándula tiroides está estructurada por miles de folículos tiroideos, pequeñas esferas que miden en el hombre de 0,2 a $0,9 \mathrm{~mm}$ de diámetro, compuestos por un grupo de células foliculares, unidad estructural y funcional de la glándula que presentan un epitelio simple cúbico que limita espacios esféricos centrales llenos de sustancia gelatinosa: el coloide, región en la cual se almacenan las hormonas T4 y T3 unidas a una glucoproteina: tiroglobulina (Junqueira \& Carneiro, 2000).

En el hombre a las 12 semanas de gestación la glándula sintetiza y segrega hormonas tiroideas, bajo la estimulación del hipotálamo a través de la hormona TRH, la que a su vez estimula la liberación de TSH por parte de la hipófisis del feto (Silbernagl \& Despopoulos, 2008).
Las células foliculares tienen la capacidad de sintetizar, almacenar y secretar dos hormonas importantes, la tiroxina y la triyodotironina, denominadas habitualmente $\mathrm{T} 4$ y T3 respectivamente. Estas hormonas aumentan el ritmo basal de utilización de oxigeno y el índice metabólico basal, así como la tasa correspondiente de producción de calor, para adaptarlas a las alteraciones de las necesidades energéticas, del abastecimiento calórico y del ambiente térmico, igualmente esta glándula presenta las células C o parafoliculares encargadas de secretar calcitonina, una hormona importante que ayuda a disminuir las concentraciones sanguíneas de calcio (Gartner et al., 2008).

Esta glándula suele experimentar dos tipos de trastornos endocrinos o metabólicos denominados como tirotoxicosis: el hipertiroidismo generado por exceso en la función de la tiroides que conlleva a una hipersecreción de Tiroxina (T4) libre o triyodotironina (T3) libre o de ambas y niveles plasmáticos anormales y elevados de las citadas hormonas (Reid \& Wheeler, 2005). Contrariamente a esta afección, encontramos el hipotiroidismo generado por un marcado déficit en la síntesis y secreción de hormonas tiroideas producto básicamente de una insuficiencia en el consumo de yodo (Raza \& Mahmood, 2013).

\footnotetext{
" Depto de Ciencias Básicas, Facultad de Medicina, Universidad de La Frontera, Temuco, Chile.

** Instituto de Ciencias Marinas y Limnológicas, Universidad Austral, Valdivia, Chile.

Proyecto DI-UFRO 15-0005.
} 
Las células de los folículos tiroideos se sustentan sobre una lámina basal y muestran toda las características de aquellas que simultaneamente sintetizan, secretan, absorben y digieren proteínas, por tanto, en su citoplasma encontramos abundante retículo endoplásmico rugoso (RER) y una cantidad moderada de mitocondrias. El núcleo generalmente es esférico y situado en el centro de la célula. En el polo apical se observa una zona de Golgi discreta y gránulos de secreción con las características del coloide folicular, además de un número moderado de microvellosidades. En esta región se encuentra también lisosomas y algunas vacuolas de gran tamaño (Junqueira \& Carneiro).

Por otro lado las células parafoliculares o célula C, se encuentran en forma individual o pueden formar racimos pequeños de células en la periferia de los folículos tiroideos, poseen una pequeña cantidad de RER, mitocondrias alargadas y complejo de Golgi prominente. En su citoplasma se encuentran numerosos gránulos que contienen calcitonina. El núcleo es generalmente redondo. Estas células entonces poseen las típicas características ultraestructurales de secreción polipéptidica (Junqueira \& Carneiro).

Nosotros hemos estudiado y demostrado que las inducciones con láser infrarrojo (LIR) sobre hepatocitos de rata genera una significativa activación de la función celular determinada por notables diferencias en los volúmenes de constituyentes celulares tanto citoplasmáticos: retículo endoplasmático rugoso, mitocondrias, gránulos de glicógeno, como nucleares: poros nucleares, tipos de cromatina y nucléolos. Igualmente en las áreas nucleares y celulares (Cornejo et al., 2012).

En base a lo aquí presentado, el objetivo fundamental del presente trabajo está orientado a determinar las distintas modificaciones que en este tipo celular sintetizador y secretor de la glándula tiroides se generan cuando son estimuladas con el emisiones del LIR.

\section{MATERIAL Y MÉTODO}

Para el estudio con microscopía óptica las tiroides normales y estimuladas durante 15 días consecutivos con LIR $16 \mathrm{~J} / \mathrm{cm}^{2}$ fueron fijadas en formalina al $10 \%$ para enseguida proceder a la deshidratación en batería creciente de alcoholes de $50 \%$ a $100 \%$ por dos horas, posteriormente fueron incluídas en Paraplast durante una noche. Se realizaron cortes seriados de $7 \mathrm{~mm}$ de espesor fijándoles a portaobjetos albuminizados y dejando secar por $24 \mathrm{~h}$. El proceso de tinción requirió desparafinar con Xilol por 40 min y proceder a la tinción citoplasmática con eosina por
5 min y a la nuclear con hematoxilina por 3, además de tinción con Azul de Toluidina. Luego de un lavado con agua se deshidrataron los cortes con batería crecientes de alcoholes otorgándoles transparencia mediante xilol fenicado por 5 min. Finalmente se realizó el montaje de los cortes en medio Permount dejando secar por $24 \mathrm{~h}$ a temperatura ambiente.

Los respectivos cortes de las citadas tiroides fueron observadas y fotografiadas en un microscopio Carl Zeiss modelo Axioskop 40 acondicionado con cámara digital incorporada.

Para la determinación de áreas tanto celulares como nucleares, y perímetros se utilizó el Programa Sigma Scan Pro 5.0.

\section{RESULTADOS}

Tiroides de rata tanto normales y estimuladas mediante láser infrarrojo con dosis de $16 \mathrm{~J} / \mathrm{cm}^{2}$ fueron estudiadas detallándose las diferencias de sus componentes estructurales (Figs. 1, 2 y 3). Los datos morfométricos se muestran en las Tablas I y II). El promedio de células foliculares evaluadas en 100 folículos tiroideos pertenecientes a tiroides normales fue de 19 y en tiroides estimulada con dosis de láser infrarrojo con dosis de $16 \mathrm{~J} / \mathrm{cm}^{2}$ fue de 28 .

En los cortes teñidos con Azul de Toluidina de la tiroides estimulada con láser $16 \mathrm{~J} / \mathrm{cm}^{2}$ (Fig. 3) se observan folículos de diferentes morfologías, donde la mayor parte de ellos eran ovalados, de márgenes y tamaño irregulares, rodeados por un epitelio cúbico o cilíndrico cuyo contenido corresponde a un coloide oscuro con alta afinidad al colorante su superficie externa se presentó híperhémica con capilares engrosados que establecen estrecho contacto con el epitelio formando indentaciones con las células foliculares.

Además se visualizan escasos folículos esféricos con márgenes lisos de epitelio cúbico bajo, saturados de coloide claro y homogéneo, rodeados por una fina red de capilares y finalmente aparecen estados intermedios con coloide claro y margen regular que muestran inicio del aumento de la vascularización.

En la tiroides con inducciones de láser infrarrojo se observa tanto un drástico aumento en los diámetros de los capilares como igualmente incremento en la superficie de contacto de estos vasos con las células epiteliales de la glándula estimulada en comparación con su contrapartida normal. 
Tabla I. Promedio de áreas y perímetros celulares expresados en micrones cuadrados pertenecientes a 100 células foliculares de tiroides tanto normales como estimuladas con laser infrarrojo con dosis de $16 \mathrm{~J} / \mathrm{cm}^{2}$

\begin{tabular}{|c|c|c|}
\hline & Tiroides normal & Tiroides $16 \mathrm{~J} / \mathrm{cm}^{2}$ \\
\hline Area celular & 18,7 & 24,7 \\
\hline Perímetro celular & 17,3 & 20,8 \\
\hline
\end{tabular}

Tabla II. Promedio de áreas y perímetros expresados en micrones cuadrados correspondiente a núcleos pertenecientes a 100 células foliculares de tiroides de rata tanto normales como estimuladas con dosis de láser infrarrojo $16 \mathrm{~J} / \mathrm{cm}^{2}$

\begin{tabular}{lcc}
\hline & Tiroides normal & Tiroides $\mathbf{1 6} \mathbf{~ J} / \mathbf{c m}^{\mathbf{2}}$ \\
\hline Area nuclear & 6,5 & 9,6 \\
Perímetro nuclear & 11,1 & 13,4 \\
\hline
\end{tabular}

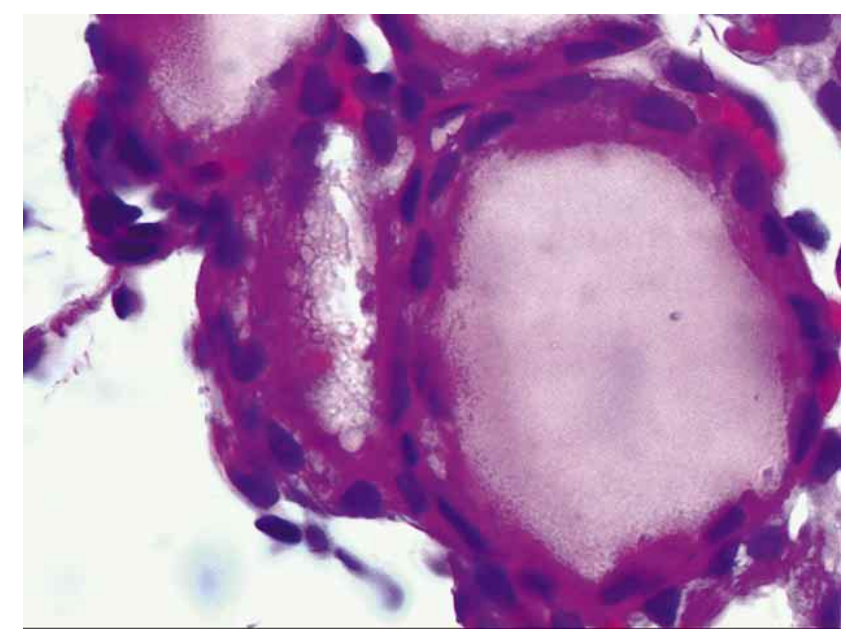

Fig. 1. Micrografía óptica correspondiente a células foliculares y coloide tiroideo de rata normales coloreadas con HematoxilinaEosina (1000X).

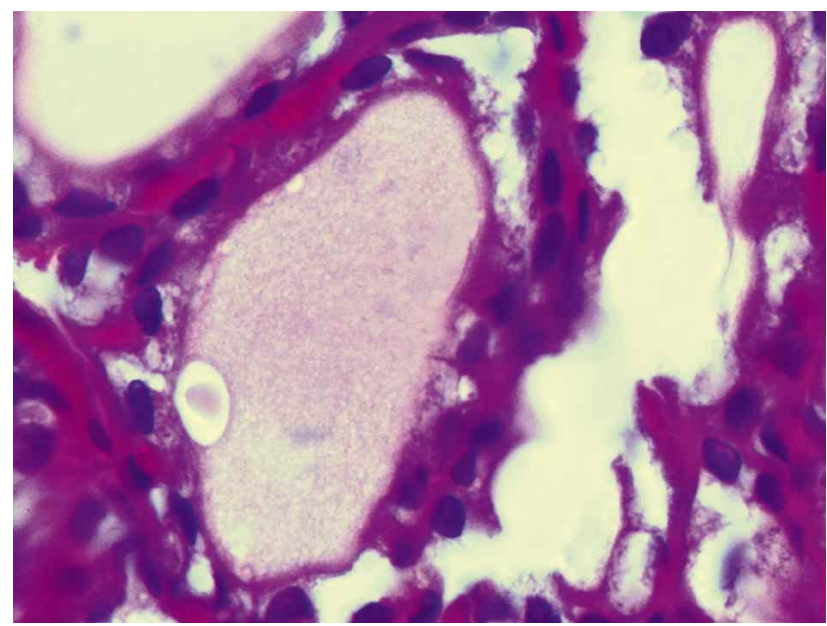

Fig. 2. Micrografía óptica correspondiente a células foliculares y coloide tiroideo de rata estimulada con dosis de láser infrarrojo 16 $\mathrm{J} / \mathrm{cm}^{2}$ teñidas con Hematoxilina-Eosina (1000X).

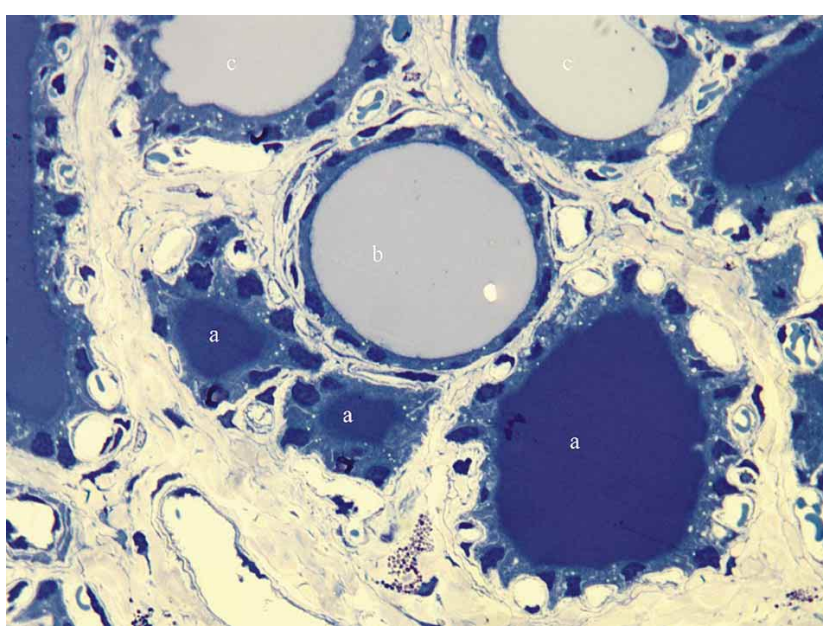

Fig. 3. Micrografía óptica de células foliculares y coloideo tiroideo de rata estimulada con láser infrarrojo con dosis de $16 \mathrm{~J} / \mathrm{cm}^{2}$ teñida con Azul de Toluidina (1000X).

\section{DISCUSIÓN}

Los resultados obtenidos en el presente trabajo describen con claridad que las estimulaciones con una dosis de láser infrarrojo equivalente a $16 \mathrm{~J} / \mathrm{cm}^{2}$ generan una seria de modificaciones tanto en las células foliculares, en su número como en la consistencia del coloides tiroideo y en la disposición de capilares en la glándula.

Con respecto a nuestros hallazgos cuantificando importantes incrementos de áreas y perímetros tanto celulares como nucleares y en el número de células foliculares pertenecientes a tiroides irradiadas comparadas con las normales, estos resultados son coincidentes con los logrados por Parrado et al. (1999) los cuales cuando estimulan tiroides con dosis de LIR de $46.8 \mathrm{~J} / \mathrm{cm}^{2}$ visualizan aumento del volumen folicular y por ende del coloides representado un incremento en la síntesis y secreción hormonal. Situación semejante describe Rajkovic et al. (2003) los que reportan que al someter ratas a campos electromagnéticos se visualizan significativos aumentos en la densidad de volumen de folículos y coloide tiroideos. De igual manera, HartoftNielsen et al., (2005) plantean que existe equilibrio entre cantidad de coloide y estructuración folicular.

Un nuevo ejemplo de efectos generados por inducciones de laser infrarrojo sobre tiroides es el trabajo de Azevedo et al. (2005) quienes describen incrementos en la síntesis y secreción hormonales de T3 y T4 al estimular tiroides de ratones con dosis de $4 \mathrm{~J} / \mathrm{cm}^{2}$. Sin embargo, AlMustawfi et al. (2010) al estimular tiroides pertenecientes a conejos hembras con dosis infrarrojas de $4 \mathrm{~J} / \mathrm{cm}^{2}$ describen 
una baja considerable en la síntesis y secreción de T3 y T4 describiendo señales de hipotiroidismo.

En lo relativo a la presencia de capilares de diámetro dilatado descrito en tiroides estimuladas, nuestros resultados son coincidentes con los emitidos por Parrado et al. (1990) quienes estimulando la glándula con dosis de 46,8 J/ $\mathrm{cm}^{2}$ visualizan un considerable aumento en el área luminal del endotelio, un aumento en la densidad de volumen de los capilares y una considerable reducción del espesor de vasos. En directa relación con estas observaciones, Vidal et al. (2002) irradiando tiroides de ratas con dosis de $46,8 \mathrm{~J} / \mathrm{cm}^{2}$ describen que como resultados de dichas estimulaciones se genera crecimiento y maduración de las células endoteliales, variaciones en su espesor y reducción del lumen de dichos capilares.

Desde el punto de vista ultraestructural Vidal et al. (2000) describen variaciones en las células foliculares producto de las estimulaciones infrarrojas con dosis de 46,8 J/ $\mathrm{cm}^{2}$ precisando cambios en los organelos relacionados a síntesis y secreción hormonal destacando particularmente en un aumento de gotas de coloides y lisosomas, dilatación de las cisternas de retículo endoplasmático rugoso y reducción del complejo de Golgi.

Dependiendo del grado de estimulación de la glándula tiroides por acción de la hormona adeno-hipofisiaria tiroestimulante (TSH), las células foliculares varían su altura de cúbicas bajas a cilíndricas. Cuando no existe estimulación por TSH las células se aplanan y el coloide se va acumulando aumentando el díámetro folicular.

En tiroides con patologías como el caso de hipertiroidismo (Bocio o enfermedad de Graves) aumenta la utilización del coloides, las células se hacen cilíndricas y disminuye la cantidad de coloide y el lumen de los folículos se hace irregular. En el caso de la estimulación con láser también aumenta la altura de las células lo que estaría indicando una estimulación de la glándula. Por otro lado encontramos que las células foliculares se hacen irregulares en el borde apical que contacta con el coloide lo que aumenta la superficie de contacto facilitando la absorción de las hormonas tiroídeas. Los folículos presentan contornos irregulares (Rubin et al., 2005)

Esta situación así planteada aparece claramente representada en el caso de la estimulación con láser puesto que se observa también aumento de altura de las células foliculares lo que estaría indicando una estimulación de la glándula. Por otro lado también encontramos que las células foliculares se hacen irregulares en el borde apical que contacta con el coloide lo que aumenta la superficie de contacto facilitando la absorción de las hormonas tiroideas y de igual manera los foliculos también presentan contornos irregulares.

CORNEJO, R.; JARAMILLO, R.; GARRIDO, O. \& VERGARA, L. Infrared laser effect on thyroid cells. Int. J. Morphol., 34(2):498502, 2016.

SUMMARY: Ten 4-month-old Sprague Dawley rats weighing approximately $250 \mathrm{~g}$ were divided into two groups of 5 animals each. Group A was the control and the animals in group B received thyroid stimulation with infrared laser in a dose of $16 \mathrm{~J} / \mathrm{cm}^{2}$ for 15 consecutive days. Subsequently, rats were euthanized and thyroids were removed and processed for optical microscopy. From both cell types thyroid histological slides and micrographs were obtained with final increases of 400 and 1000X. Morphometric analysis determined the number, areas and cell perimeter as well as colloidal dispersion and presence of blood vessels in 100 follicular cells. Analysis of the results among the 100 follicular cells belonging to normal and stimulated thyroids revealed marked differences in all the analyzed components, which could translate into different functionalities in the metabolism of the respective glands.

KEY WORDS: Thyroid cells; Follicular cells; Morphometry; Infrared laser.

\section{REFERENCIAS BIBLIOGRÁFICAS}

Al-Mustawfi, N. S.; Al-Azawi, T. S. \& Mohammed, I. F. R. Effect of laser treatment on thyroid gland hormones in female rabbits. Iraqi J. Vet. Sci., 25(2):61-4, 2011

Azevedo, L. H.; Aranha, A. C.; Stolf, S. F.; Eduardo, Cde. P. \& Vieira, M. M. Evaluation of low intensity laser effects on the thyroid gland of male mice. Photomed. Laser Surg., 23(6):567$570,2005$.
Cornejo, R.; Matamala, F.; Silva, H.; Garrido, O. \& Saéz, L. Persistence of the effects of $6 \mathrm{~J} / \mathrm{cm}^{2}$ infrared laser in rat hepatocytes. Int. J. Morphol., 30(2):467-72, 2012.

Gartner, L. P.; Hiatt, J. L. \& Araiza, M. E. Atlas de Histología. $3^{a}$ ed. México D. F., MacGraw-Hill, 2008. pp.193-208.

Hartoft-Nielsen, M. L.; Rasmussen, A. K.; Feldt-Rasmussen, U.; 
Buschard, K. \& Bock, T. Estimation of number of follicles, volume of colloid and inner follicular surface area in the thyroid gland of rats. J. Anat., 207(2):117-24, 2005.

Junqueira, L. C. \& Carneiro, J. Histología Básica. $11^{\text {a }}$ ed. Rio de Janeiro, Guanabara Koogan, 2000. pp.417-9.

Parrado, C.; Carrillo de Albornoz, F.; Vidal, L. \& Pérez de Vargas, I. A quantitative investigation of microvascular changes in the thyroid gland after infrared (IR) laser radiation. Histol. Histophatol., 14(4):1067-71, 1999.

Parrado, C.; Peláez, A.; Vidal, L. \& Pérez de Vargas, I. Quantitative study of the morphological changes in the thyroid gland following IR laser radiation. Lasers Med. Sci., 5(1):77-80, 1990.

Rajkovic, V.; Matavulj, M.; Gledic, D. \& Lazetic, B. Evaluation of rat thyroid gland morphophysiological status after three months exposure to $50 \mathrm{~Hz}$ electromagnetic field. Tissue Cell, 35(3):223-31, 2003.

Raza, S. A. \& Mahmood, N. Subclinical hypothyroidism: Controversies to consensus. Indian J. Endocrinol. Metab., 17 (Suppl. 3):S636-42, 2013.

Reid, J. R. \& Wheeler, S. F. Hyperthyroidism: diagnosis and treatment. Am. Fam. Physician, 72(4):623-30, 2005.

Rubin, E.; Gorstein, F.; Rubin, R.; Schwarting, R. \& Strayer, D. Rubins's Pathology, Clinopatologic Foundations of Medicine. $4^{\mathrm{a}}$ ed. Baltimore, Lippincott Williams \& Wilkins, 2005. pp.250-70.

Silbernagl, L. \& Despopoulos, A. Fisiología. Texto y Atlas. Madrid, Médica Panamericana, 2008. pp.48-64.

Silverthorn, D. U. Fisiología Humana: Un Enfoque Integrado. $4^{\mathrm{a}}$ ed. Madrid, Editorial Médica Panamericana, 2008. pp.85-100.

Vidal, L.; Perez de Vargas, I. \& Mata, G. Ultrastructural changes in thyroid follicular cells during normal postnatal development and after infrared laser radiation. Lasers Med. Sci., 15(4):22737,2000 .

Vidal, L.; Ortíz, M. \& Pérez de Vargas, I. Ultrastructural changes in thyroid perifollicular capillaries during normal postnatal development and after infrared laser radiation. Lasers Med. Sci., 17(3):187-97, 2002.

\author{
Dirección para Correspondencia: \\ Dr. Ricardo Cornejo \\ Facultad de Medicina \\ Universidad de La Frontera \\ Casilla 54-D \\ Temuco \\ CHILE
}

Email: rene.cornejo@ufrontera.cl

Recibido : 05-01-2016

Aceptado: 20-04-2016 